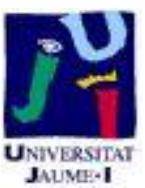

Título artículo / Títol article: On the distributional properties of size, profit and growth of Icelandic firms

Autores / Autors

Einar Jón Erlingsson, Simone Alfarano, Marco Raberto, Hlynur Stefánsson

Revista:

Journal of Economic Interaction and Coordination

Versión / Versió:

Postprint del autor

Cita bibliográfica / Cita

ERLINGSSON, Einar Jón; ALFARANO, Simone; bibliogràfica (ISO 690):

RABERTO, Marco; STEFÁNSSON, Hlynur

url Repositori UJI:

http://hdl.handle.net/10234/72346 


\section{MPRA \\ Munich Personal RePEc Archive}

\section{On the distributional properties of size, pro fit and growth of Icelandic firms}

Einar Jón Erlingsson and Simone Alfarano and Marco

Raberto and Hlynur Stefánsson

Universitat Jaume I de Castellò

January 2012

Online at http://mpra.ub.uni-muenchen.de/35857/

MPRA Paper No. 35857, posted 11. January 2012 20:41 UTC 


\title{
On the distributional properties of size, profit and growth of Icelandic firms
}

\author{
Einar Jón Erlingsson • Simone Alfarano • \\ Marco Raberto • Hlynur Stefánsson
}

\begin{abstract}
In this paper, we analyze the distributional properties of the balance sheets of Icelandic firms by performing an empirical analysis of total assets, profit rates and growth rates using a data set of 2818 Icelandic firms during the period 2000-2009. We find that the firms size measure, i.e. total assets, have the same heavy tail characteristics as various studies have shown, e.g. for U.S. and Italian firms. The heavy tail nature of the total assets distribution seems to be robust w.r.t. a boom-bust cycle of the economy as well as special characteristics of Icelandic firms, e.g. their relatively small size and private ownership. Another important finding is that the profit rates, or return on assets, of Icelandic firms follow a Laplace like distribution similar to U.S. firms. Additionally, we identified deviations from the distributional regularities, namely the power law behavior of firms' size and laplacian distributions of growth and profit rates, during the booming period of the economy 2005-2007.
\end{abstract}

Keywords Firm size · Profit rates · Growth rates · Power law ·

Laplace distribution · Icelandic firms

JEL classification $\mathrm{C} 12 \cdot \mathrm{D} 01 \cdot \mathrm{D} 22$

Corresponding author: Einar Jón Erlingsson, E-mail:einare09@ru.is

E. J. Erlingsson · H. Stefánsson

Reykjavik University, Menntavegur 1, 101 Reykjavik, Iceland

S. Alfarano

Universitat Jaume I, Campus del Riu Sec, 12071 Castellon, Spain

M. Raberto

DOGE.I, Università di Genova, Via Opera Pia 11a, 16145 Genova, Italy 


\section{Introduction}

Firms drive economic growth through investment and innovation and are an important part of any economy. In this paper, we analyze the distributional properties of the balance sheets of Icelandic firms during the period 2000-2009. First we analyze a measure of firms size, namely the level of total assets, then we consider the growth rates of firms' total assets, and finally we look at profit rates, defined as earnings before interest and taxes divided by total assets. It is worth noting that the Iceland economy, for its small dimension and the recent boom-bust cycle, is a peculiar and interesting case study for testing the presence of the distributional properties that have been recently described in the literature, both for US (Axtell 2001, Podobnik et al. 2010 and Alfarano et al. 2012) and Italian (Bottazzi and Secchi 2006 and Cirillo 2010) firms, namely power law behavior of firm size and Laplacian distribution of firms growth and profit rates. In the last decade, the Icelandic economy witnessed a dramatic increase and decrease in asset prices as well as a housing bubble. Twelve month inflation rates reached $20 \%$, the currency, the Icelandic Kronur (ISK), lost about half of its value w.r.t. the Euro in 2008, and almost the entire banking system collapsed in the space of a week in early October 2008. Furthermore, most of the firms in Iceland are privately owned and are not traded on any stock exchange, unlike data sets used in most studies of firms dynamics known to the authors. Therefore, it is interesting to analyze whether distributional properties of firms size, profit and growth rates are robust w.r.t. a boom-bust cycle of a small open economy inhabited mostly by privately owned firms.

Analysis of the measures of firms' size have a long history in the literature. Since the seminal work of Gibrat (1931) it has been known that the distribution of firms size, proxied by the number of employees, follows a right skew distribution. According to Gibrat's law, the growth rate of firms is independent of its size, giving rise to a log-normal distribution. It seems that the log-normal distribution does not account for the power law behavior in the tail of the firm size distribution. From a historical perspective, the model introduced by Champernowne (1953) with the presence of a minimum firm size ${ }^{1}$ can account for the power law behavior in the tail. The heavy-tailed distribution found for firm size has been modeled in various ways, see De Wit (2005) for an overview. Perhaps the best known of these methods is the multiplicative process (Simon and Bonini 1958, and Ijiri and Simon 1974), summarized by the saying "the rich get richer". Recent models of heavy-tailed distributions of various size related phenomena include the model of Atalay et al. (2011) of a buyer-seller network for US production firms and the random group formation model of Baek et al. (2011). The power-law behavior of the upper tail of firm's size distribution has been verified for various periods and economies, e.g. for U.S. firms by Axtell (2001), Podobnik et al. (2010) and Simon and Bonini

\footnotetext{
1 The original model by Champernowne has been constructed to account for the distribution of income. However the basic mechanism can also be adapted to the firms growth process.
} 
(1958), and for Italian firms by Cirillo (2010) and Cirillo and Hüsler (2009). The recent contribution of Gabaix (2009) reviews both the empirical literature of power law behavior in economic and social systems as well as several classes of stochastic models to generate such a scaling behavior.

In a recent paper, Alfarano et al. (2012) show that the profit rate distribution of large publicly traded US companies is well described by a Laplace distribution. Using the statistical equilibrium approach, they relate the emergence of the Laplace distribution to the notion of classical competition. The same tent like distribution has been found to fit reasonably well growth rates of firms, see e.g. Bottazzi and Secchi (2006) and Alfarano and Milakovic (2008).

A further objective of this work has been to gather important stylized facts and descriptive statistics of the Icelandic economy to be used for the validation and calibration of agent-based macroeconomic models, which recently have been recognized (Farmer and Foley 2009) as an alternative to traditional dynamic stochastic general equilibrium (DSGE) models, see e.g. Smets et al. (2002), that have been used by economic policy makers during the past decade. These new agent-based models, e.g. EURACE (Cincotti et al. 2010 and Raberto et al. 2011), rely on stylized facts of the economy for calibration and validation.

In section two we will give a detailed description of our data set, while in sections three and four we will analyze the distributional properties of total assets, used as a measure of firm size, and profit and growth rates of Icelandic firms respectively. In section five we present our results.

\section{Data set}

The data set used in this study is public information attained from annual reports of Icelandic firms collected by the Icelandic Internal Revenue Directorate (RSK). The RSK does not give access to digital (computerized) data. Therefore the authors turned to a third party data provider, Creditinfo hf. ${ }^{2}$.

Data from 2818 Icelandic firms were collected for the years 2000-2009 giving a total of 11084 observations. The firms in the data set have minimum assets of 100 million ISK $^{3}$ and belong to various industries such as manufacturing, service, retail and fishing. The data set does not contain banks, insurance firms or other financial institutions. In Iceland only a very limited number of firms are listed on the Icelandic stock exchange, so the vast majority of the firms in the data set are privately owned firms.

When analyzing data of firms profit and growth rates we are interested in relatively large, long lived firms for the sake of consistency with previous work (Alfarano et al. 2012 and Bottazzi and Secchi 2006). To get this subset of firms we select the firms present in the year 2000 and gather all observations

\footnotetext{
2 Creditinfo hf. specializes in providing credit information about Icelandic firms., http://www.creditinfo.is

3 The average exchange rate of the ISK has been approx. 162 ISK for 1 EUR in April 2011
} 


\begin{tabular}{ccccc}
\hline Year & No. obs. & Mean TA & No. obs. Long lived & Mean T A, Long lived \\
\hline 2000 & 518 & 1.272 .575 & 518 & 1.272 .575 \\
2001 & 598 & 1.309 .588 & 421 & 1.635 .462 \\
2002 & 726 & 1.143 .999 & 431 & 1.601 .477 \\
2003 & 870 & 1.057 .349 & 441 & 1.513 .737 \\
2004 & 1007 & 1.160 .869 & 430 & 1.977 .509 \\
2005 & 1263 & 1.385 .675 & 424 & 2.590 .019 \\
2006 & 1618 & 1.296 .920 & 415 & 2.737 .960 \\
2007 & 1971 & 1.643 .282 & 426 & 3.961 .210 \\
2008 & 1889 & 1.744 .903 & 382 & 3.981 .384 \\
2009 & 624 & 1.315 .863 & 136 & 1.836 .308 \\
Aggregated & 11084 & 1.404 .404 & 4024 & 2.298 .303 \\
\hline
\end{tabular}

Table 1 Columns two and three represent the whole data set while columns four and five represent long lived firms. All monetary values given are in thousands of ISK.

for these firms in the years 2001-2009. This will leave out any firms established after the year 2000 and since all firms in the data set were active at the end of the period considered, 2000-2009, give us a good subset of long lived firms in Iceland.

Our data set is comprised of $5-6 \%$ of all firms in Iceland, representing about half of the total assets of firms in Iceland. When considering long lived firms, they represent about $1.3 \%$ of the total number of firms in Iceland with about one quarter of the total assets. Table 1 shows some descriptive statistics of the data set, both w.r.t all firms as well as long lived firms.

There are some peculiarities in the Icelandic data that need to be noted. Firstly, according to Icelandic law (no. 696/1996 ${ }^{4}$ ) revenues are defined as the sum of revenues from core operations and other revenues. No further details are given for revenues, e.g. sales are not given explicitly. Secondly, firms in Iceland can turn in contracted forms of the annual report (law no. 694/1996) if they fulfill certain conditions ${ }^{5}$. If firms hand in contracted forms of the annual report no information is given about revenues and costs, while the difference of the two, defined as earnings before interest and taxes, EBIT, is given for all firms in the data set. Unfortunately it seems that firms in Iceland have a tendency to turn in the contracted form of the annual report if they possibly can. As a result revenues and cost are difficult to analyze. Thirdly, although the RSK can enforce fines for not handing in annual reports it has not done so in the past. In some cases firms have taken advantage of this and not filed annual reports with the RSK, with the end result of missing observations in our data set.

These peculiarities aside, the data set gives the opportunity to study the distributional properties of firms balance sheet entries during a boom-bust cycle of a small open economy.

4 All Icelandic law can be found on-line at: http://www.althingi.is

5 These conditions are mostly related to size measures, small firms with little turnover can file contracted forms of the annual report. The law also allows firms to file contracted forms of the annual report for reasons of competition, i.e. if the firms can argue that reporting full annual report might reversely affect competition. 


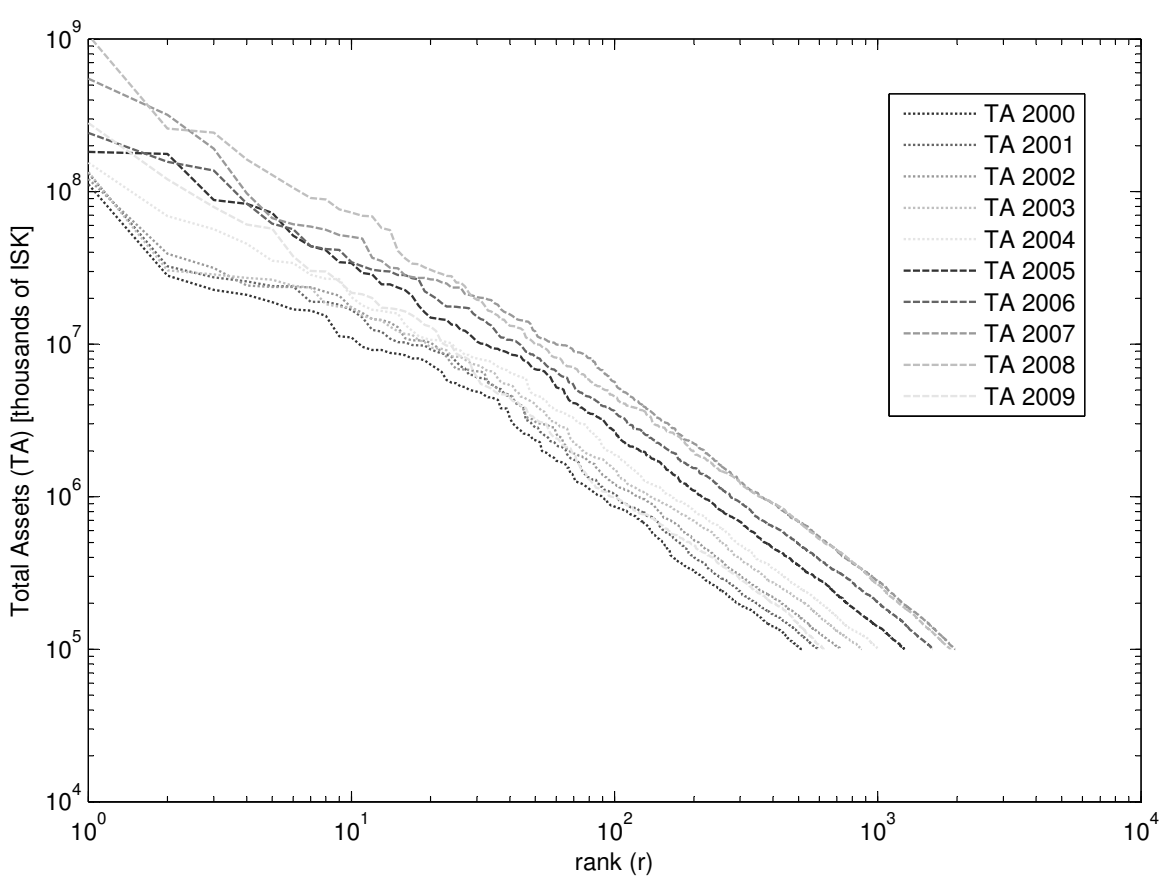

Fig. 1 Zipf plot of $T A$, disaggregated for each year, shown on a log-log scale. The variables exhibit classic power-law behavior.

\section{Total Assets}

One of the benchmarks for any measure of firm size is that it is well described by a power-law distribution. Firm size is often measured by the number of employees it has, by the amount of sales it generates or, as in our case, by the book value of total assets $(T A)$. Note that when analyzing $T A$ we use the entire data set.

We consider a power-law probability density function (PDF) defined as:

$$
f(x \mid \beta) \sim x^{-\beta}
$$

Using this PDF of the power-law distribution we can estimate the exponent, $\beta$, using ordinary least squares regression by:

$$
\hat{\beta}=\frac{\sum_{i=1}^{N}\left(\log r_{i}-\log \hat{r}\right) \log T A_{i}}{\sum_{i=1}^{N}\left(\log r_{i}-\log \hat{r}\right)}
$$

Where $r$ is the ordered rank of firms from the largest to the smallest, $\mathrm{N}$ is the total number of samples and $\hat{r}$ is the mean of the rank. The error can be estimated in the standard way.

It seems from viewing figure 1 that there is a power-law regime in the Zipf plot of $T A$ of Icelandic firms. Table 2 shows the OLS estimated exponent, $\beta$, for each year present in the data set as well as the estimated standard error 


\begin{tabular}{cccc}
\hline Year & Exponent, $\beta$ & Exponent, $\beta_{K S}$ & KS statistic \\
\hline 2000 & $\mathbf{1 . 2 5}(\mathbf{0 . 0 4})$ & $\mathbf{1 . 2 7}(\mathbf{0 . 0 4})$ & 0.03 \\
2001 & $\mathbf{1 . 2 7}(\mathbf{0 . 0 4})$ & $\mathbf{1 . 3 0}(\mathbf{0 . 0 4})$ & 0.02 \\
2002 & $1.22(0.04)$ & $\mathbf{1 . 2 6}(\mathbf{0 . 0 4})$ & 0.02 \\
2003 & $1.19(0.03)$ & $\mathbf{1 . 2 4}(\mathbf{0 . 0 3})$ & 0.03 \\
2004 & $1.21(0.03)$ & $\mathbf{1 . 2 7}(\mathbf{0 . 0 3})$ & 0.02 \\
2005 & $1.24(0.03)$ & $\mathbf{1 . 2 8}(\mathbf{0 . 0 3})$ & 0.03 \\
2006 & $1.22(0.03)$ & $1.28(0.03)$ & 0.03 \\
2007 & $1.27(0.02)$ & $1.35(0.02)$ & 0.03 \\
2008 & $1.27(0.02)$ & $1.35(0.02)$ & 0.04 \\
2009 & $1.30(0.04)$ & $\mathbf{1 . 3 2}(\mathbf{0 . 0 4})$ & 0.04 \\
\hline
\end{tabular}

Table 2 The exponent, $\beta$, is estimated for each year in the data set using eq. 2 , the standard error is shown in parentheses. We also provide an estimate of the exponent minimizing the Kolmogorov-Smirmov (hereby KS) statistic, $\beta_{K S}$. The last column shows the KS statistic calculated using $\beta_{K S}$ for the exponent. Bolded values of the exponents, $\beta$ and $\beta_{K S}$, in the table represent instances where we cannot reject the hypothesis that the data comes from the power-law distribution, given a $1 \%$ confidence level.

shown in parentheses. The exponent, $\beta$, is relatively stable from one year to the next, ranging from 1.19 to 1.30 when using the standard OLS estimation. We also provide an estimation of the exponent found by minimizing the Kolmogorov-Smirnov (KS) statistic, denoted $\beta_{K S}$. The fluctuation is similar as before, between 1.24-1.35. Bolded values of the exponents, $\beta$ and $\beta_{K S}$, in table 2 , represent instances where we cannot reject the hypothesis that the data come from the power-law distribution, given a $1 \%$ confidence level $^{6}$. Unfortunately, we do not have data for number of employees or sales, previously used as measures of firm size by Axtell (2001). Our results can though be compared with what Podobnik et al. (2010) found for NYSE firms; they report an exponent of about 1.4 for book value of assets for the years 2007-2009, which is consistent with our findings for $\beta$ and $\beta_{K S}$.

According to the KS statistic, we can only reject the null hypothesis that $T A$ follows a power-law distribution, using the exponent $\beta_{K S}$, during the peak of the economic boom in Iceland, 2006-2008. One possible explanation for this is the fact that an influx of relatively small firms, $0.1 \%$ of $T A$ w.r.t. the maximum $T A$ of each year, is seen in the data set of Icelandic firms during this period. This influx starts in the early years of the boom, 2003-2005, but is most apparent during the peak of the boom. These relatively small firms do not seem to be captured by the statistical equilibrium of the power-law distribution, thus rejecting the null hypothesis that the data is well described by a power-law distribution. In fact, if these very small firms are removed form the data set we cannot reject the null hypothesis that $T A$ follows a power-law distribution, using the exponent $\beta_{K S}$ and $1 \%$ confidence level, for any year in the data set ${ }^{7}$.

6 The critical values are obtained from Goldstein et al. (2004)

7 Analysis not included in table 2 but available in additional material upon request. 


\section{Statistical analysis of profit rates and growth rates}

Profit rates, also named as return on assets or $R O A$, are computed by dividing the earnings before interest and taxes $(E B I T)$ by total assets $(T A)$. Profit rates are an important measure of firms performance and are inherently linked to growth rates because many firms use internal financing to finance growth opportunities, i.e. they use part of their profits to finance investment instead of issuing new debt or equity (external financing), as rationalized by the Pecking Order Theory (Myers 1984). Notice, however, that profit rates are defined as the ratio of a flow (yearly operating gross earnings) over a stock (total asset), while growth rates are usually defined as log differences over a given time interval of a firm size measure (typically yearly sales, total assets or number of employees). Profit rates and growth rates have been shown to be well described by a Laplace distribution, see e.g. Alfarano et al. (2012) and Bottazzi and Secchi (2006). Even if profit and growth rates retain the same functional form of their empirical distributions, they might not be linked by a trivial relationship. In this section, we want to explore whether the empirically identified distributional regularity of Laplacian profit and growth rates hold for Icelandic firms.

\subsection{Theoretical framework}

In the literature on industrial dynamics several theoretical models have been introduced to reproduce the Laplacian functional form of firms growth rates, for instance Bottazzi and Secchi (2006), Stanley et al. (1996) and Delli Gatti et al. (2005). Bottazzi and Secchi (2006), in particular, empirically tested the Laplacian hypothesis by introducing a more general distributional class, the Subbotin distribution, also known as the generalized exponential-power distribution (see eq. 4 below), and by showing that the nested Laplace distribution cannot be rejected in favor of the more general Subbotin distribution for Italian manufacturing firms.

A very general framework for the Laplacian hypothesis of profit rates distribution comes out of a statistical equilibrium model introduced by Alfarano et al. (2012) and its subsequent empirical applications. More precisely, they encode the "tendency for equalization" of profit rates due to the competitive process among firms in a moment constraint of the underlying statistical distribution of profit rates. They propose the following very general measure of dispersion:

$$
\sigma=\sqrt[\alpha]{E\left[|x-m|^{\alpha}\right]}
$$

where $m$ is a measure of central tendency of the underlying distribution ${ }^{8}$. Notice that for $\alpha=2$, the previous definition is the standard deviation, while

\footnotetext{
8 Note that the measure of central tendency is the general expression to characterize a focal value of a distribution. For instance, mean, median and mode are possible alternatives of measures of central tendency.
} 


\begin{tabular}{ccccc}
\hline Year & $m_{\text {Mean }}$ & $m_{M e d}$ & $m_{K S}$ & KS statistic \\
\hline 2000 & $\mathbf{0 . 0 5 8}(0.005)$ & 0.051 & $\mathbf{0 . 0 5 7}$ & 0.93 \\
2001 & $\mathbf{0 . 0 6 2}(0.005)$ & $\mathbf{0 . 0 6 0}$ & $\mathbf{0 . 0 5 9}$ & 0.74 \\
2002 & $\mathbf{0 . 0 5 7}(0.005)$ & $\mathbf{0 . 0 5 3}$ & $\mathbf{0 . 0 5 3}$ & 0.48 \\
2003 & $0.065(0.006)$ & 0.055 & $\mathbf{0 . 0 6 2}$ & 0.99 \\
2004 & $0.071(0.005)$ & 0.058 & $\mathbf{0 . 0 6 5}$ & 0.97 \\
2005 & $0.085(0.007)$ & 0.061 & 0.073 & 1.24 \\
2006 & $0.103(0.006)$ & 0.083 & $\mathbf{0 . 0 9 1}$ & 1.09 \\
2007 & $0.097(0.007)$ & 0.067 & 0.081 & 1.48 \\
2008 & $\mathbf{0 . 0 9}(0.01)$ & $\mathbf{0 . 0 8 6}$ & $\mathbf{0 . 0 9 3}$ & 0.71 \\
2009 & $\mathbf{0 . 0 9 2}(0.008)$ & $\mathbf{0 . 0 7 9}$ & $\mathbf{0 . 0 6 2}$ & 0.76 \\
\hline
\end{tabular}

Table 3 The table shows the estimation of the measure of central tendency for the profit rate distribution, performed with three different estimators: the mean, the median and by minimizing the KS statistics. The associated errors for all three methods is the error of the mean computed with the usual standard method. The bold estimates indicate that the Laplace benchmark cannot be rejected at $1 \%$ significance level. The critical value at $1 \%$ significance level is 1.065, according to Puig and Stephens (2000).

for the case $\alpha=1$, it coincides with the absolute mean deviation. Employing the Maximum Entropy Principle, it is possible to link up the previous moment constrain to an equilibrium distribution, which turns out to be the Subbotin distribution:

$$
f(x \mid m, \sigma, \alpha)=\frac{1}{2 \sigma \alpha^{1 / \alpha} \Gamma(1+1 / \alpha)} \exp \left(-\frac{1}{\alpha}\left|\frac{x-m}{\sigma}\right|^{\alpha}\right),
$$

where $m$ is the location parameter, $\sigma$ is the scale parameter and $\alpha$ is the shape parameter. Since the Laplace distribution is nested in eq. (4) for a value of the shape parameter $\alpha=1$, the Subbotin distribution can be employed to test for the Laplace distribution of profit and growth rates at various aggregate levels. In various papers in the literature on industrial dynamics (see for instance Bottazzi and Secchi 2006), the estimation of the shape parameter of $f(x \mid m, \sigma, \alpha)$ turned out to be "close" to one in the vast majority of empirical distributions of firms' profit and growth rates. However in several cases a maximum likelihood test rejects the Laplace in favor of the Subbotin distribution. We can consider the Laplace distribution a sort of first approximation model alternative to the Gaussian. The Gaussian distribution can be, in fact, employed as a reference distributional hypothesis of growth or profit rates under the absence of economic interactions among firms. Deviations from the Gaussian distribution indicate the presence of correlations among firms, imprint of some kind of direct or indirect economic interactions. For instance, Bottazzi and Secchi (2006) have derived the Laplacian distribution of firm growth rates out of a simple model of competition among firms in an increasing return to scale environment.

\subsection{Empirical analysis of profit rates}

Contrary to the previously analyzed data set of profit rates mainly based on publicly traded US firms (see Alfarano et. al. 2012 and references therein), our 


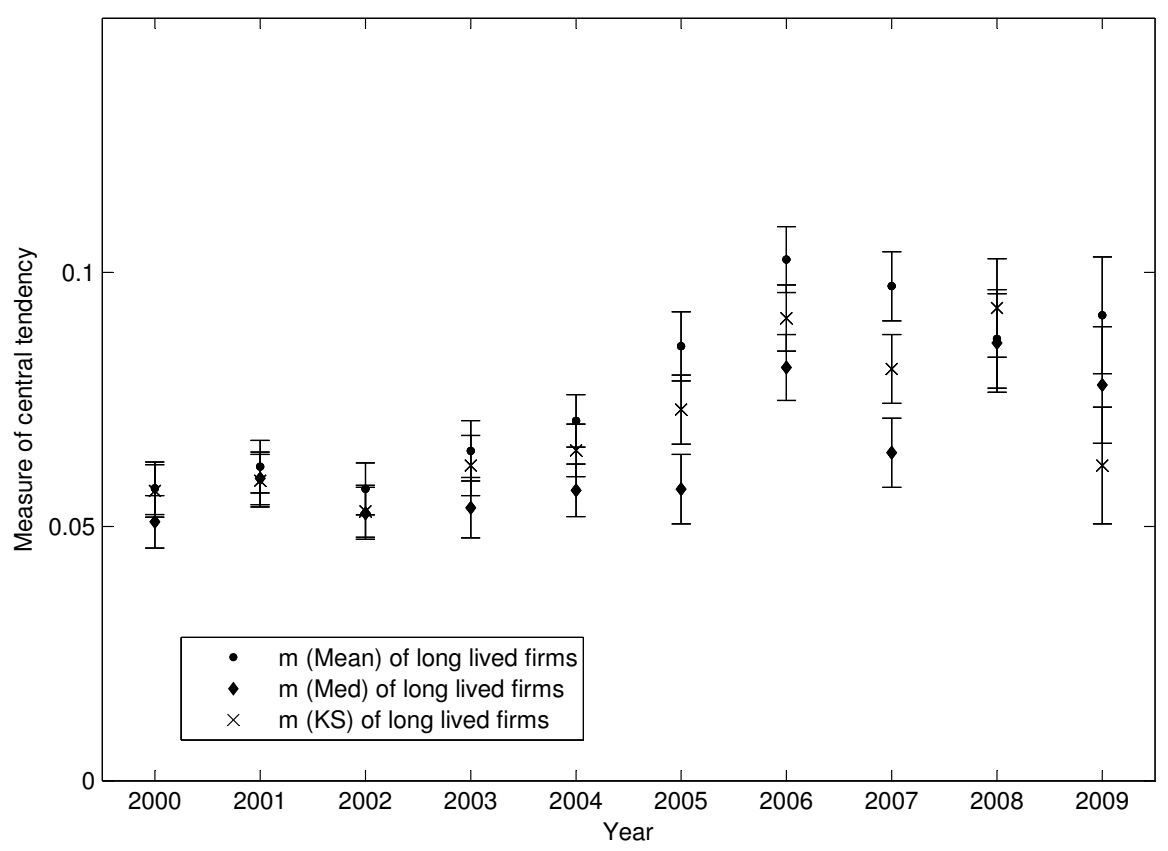

Fig. 2 The figure shows the three different measures of central tendency estimated for each year in the data set. Note the growing asymmetry of $m$ during the boom in Iceland (20052007), which coincides with the rejection of the Laplace distribution benchmark for profit rates of Icelandic firms.

data set consists of mostly privately owned firms in what can be considered a prototypical example of a small open economy. In this section, we want to analyze to which extent the Laplace distribution can do a good job in fitting the profit rates of Icelandic firms. In order to do so, we compute the goodnessof-fit using a KS statistics of the Laplace distribution in describing the data. In order to estimate the parameter $m$, we use three different measures of central tendencies: the mean, $m_{M e a n}$, the median, $m_{M e d}$, and the value which minimizes the KS statistics, $m_{K S}$. As a first approximation, we have associated to $m_{M e d}$ and $m_{K S}$ the same error as for $m_{M e a n}$, which is computed with the standard method. The scale parameter $\sigma$ is computed using the formula of the maximum likelihood for a Laplace distribution:

$$
\hat{\sigma}=\frac{1}{N} \sum_{i=1}^{N}\left|x_{i}-\hat{m}\right|,
$$

providing for $\hat{m}$ the pertinent value, namely $m_{\text {Mean }}, m_{M e d}$ or $m_{K S}$. Table 3 summarize the results of the estimation for each year in our sample. The bold value of the estimates of $m$ indicates that the Laplace distribution cannot be rejected following the KS statistic at a $1 \%$ significance level. To have an idea of the values of the KS statistics, we show in the last column its value for 
$m_{K S} \cdot{ }^{9}$ A clear-cut conclusion of our analysis is that the Laplace constitutes a good benchmark for the distribution of profit rates of Icelandic firms. In order to have an idea of the performance of the Laplace in fitting the empirical data, Figure 3 shows the profit rate distributions disaggregated per year. The Laplacian hypothesis for the profit rate distribution of long-lived firms is, then, robust if we consider a large economy like the US one, see Alfarano et. al. (2012), or a prototypical small open economy like the one of Iceland. Notice, however, that the rejection of the Laplace benchmark seems to be related the years of the economic boom (2005-2007), which coincides with an emergence of an underlying asymmetric distribution of profit rates. Table 3 and Figure 2 show in fact a significant positive difference between mean and median during the bubble period. If we make the hypothesis that the symmetric Laplace distribution is a kind of statistical equilibrium distribution which characterized a phase of 'equilibrated' growth of an economy, our tentative hypothesis is that in periods of high growth (bubble), the distribution of profit rates is characterized by a significant asymmetry. Interestingly and some how surprisingly, in the period immediately after the bubble (2008-2009), the Laplace distribution cannot be rejected, showing a fast realignment with the symmetric Laplace benchmark. Our hypothesis should be tested in different economies that in the last decade experienced a similar behavior of the Icelandic economy, namely high growth and subsequent crisis period, for instance the Spanish and Irish economies.

\subsection{Empirical analysis of growth rates}

In this section we present the empirical analysis of growth rates of Icelandic firms. The definition of annual growth rate of a firm $i$ is given by:

$$
g_{i, t}=\ln \left(\frac{T A_{i, t+1}}{T A_{i, t}}\right)
$$

where $T A_{i, t}$ are the total assets of the firm $i$ at time $t$. It has been repeatedly shown that the distribution of firm growth rates can be conveniently described by a Laplace distribution (for instance Bottazzi and Secchi (2006) and reference therein). Table 4 shows the results of the estimation exercise of the Laplace distribution using the annual growth rates of icelandic firms. Moreover, Figure 4 shows the yearly disaggregated growth rates distributions and their fitted Laplace. Contrary to the profit rates, the Laplace distribution shows a worst performance in describing the empirical probability density of growth rates. The laplacian null hypothesis is, in fact, rejected in almost all cases according to the KS test. Following our analysis of profit rates, we employ different methods for the estimation of the measure of central tendency. Interestingly, its statistics seems to have the same pattern as observed for the

\footnotetext{
9 The critical value at $1 \%$ significance level is 1.065 , according to Puig and Stephens (2000). The typical critical value for the KS test cannot be used here since the parameters of the Laplace distribution are estimated from the data sample.
} 

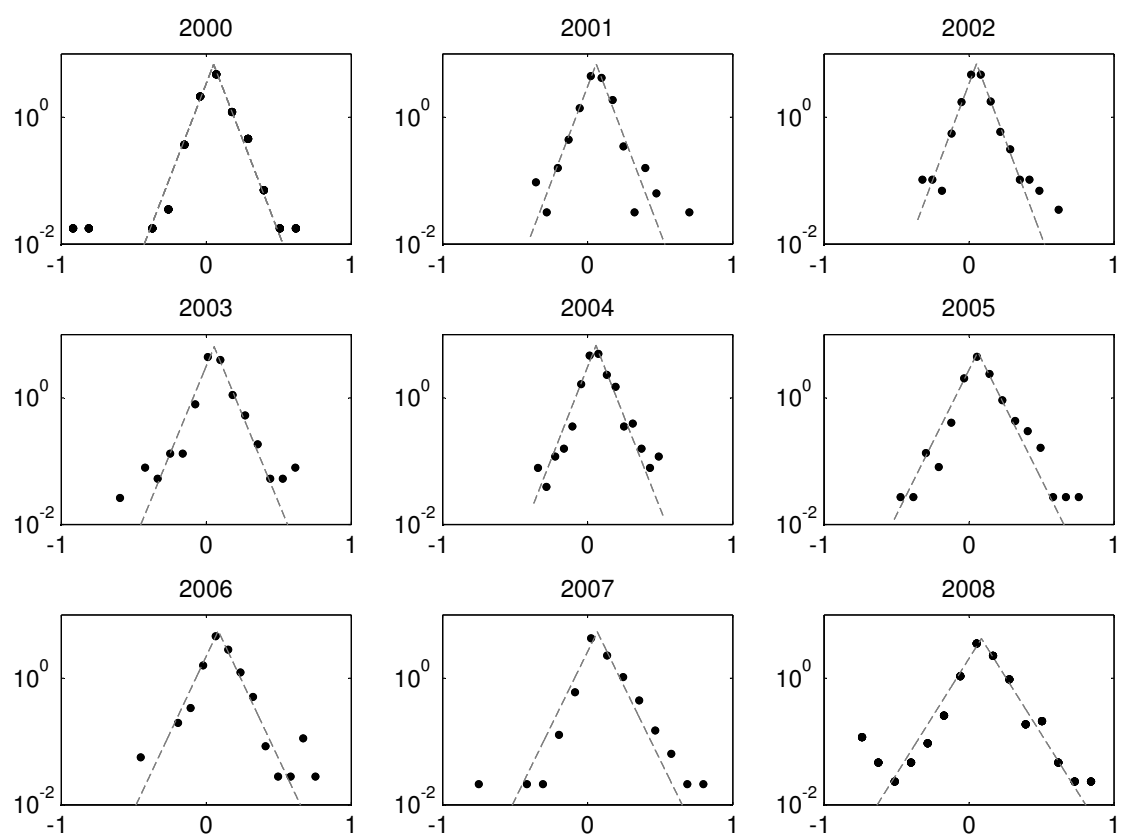

Fig. 3 The figure shows the empirical PDF of profit rates (dots) and fitted Laplace distribution (dashed line), using $m_{M e d}$ as the measure of central tendency, of long lived firms disaggregated by year shown on a semi-log scale for the years 2000-2008. The dominance of the tent shape, characteristic of the Laplace distribution, is clear.

profit rates, namely during the booming period the value of the KS statistics for the different definitions ${ }^{10}$ of $m$ increases, which coincides with the evident asymmetry of the distribution, signaled by the significant difference between mean and median.

Table 4 includes the yearly inflation rate so to let the reader compute the real growth rate. One can then observe a negative real growth rate in the period 2001-02 (related to the crash after the dot.com bubble) and in the crash of 2008 and 2009. To a negative real growth corresponds a significantly positive "average" profit rate, which can probably be linked to a shrinking phase of firms in order to increase profitability.

All in all, even if the two unconditional distribution of profit and growth rates might be more or less satisfactorily described by the underlying benchmark distribution, namely the Laplace, they exhibits some remarkable differences. The dispersion of the profit rates is much smaller than the growth rates (which is apparent from a simple comparison between Figures 3 and 4), and, more interestingly, it seems that the average profit rate is much less volatile than the average growth rate (see Tables 3 and 4 ). It seems that there is a much

\footnotetext{
10 Notice that in the Table 4, we have shown just the KS statistics for $m_{K S}$. The other values are in additional material upon request.
} 

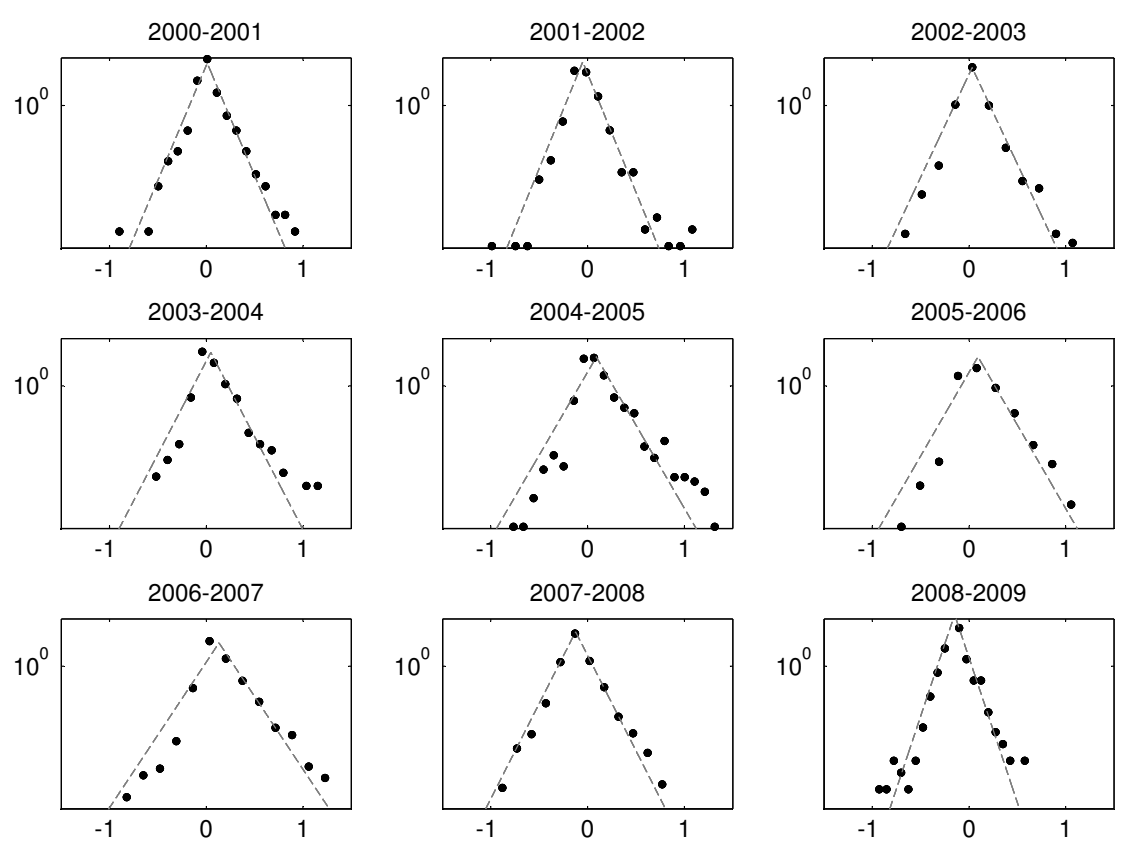

Fig. 4 The figure shows the empirical PDF of growth rates (dots) and fitted Laplace distribution (dashed line), using $g_{M e d}$ as the measure of central tendency, of long lived firms disaggregated by year shown on a semi-log scale for the years 2000-2009.

\begin{tabular}{cccccc}
\hline Year & $g_{\text {Mean }}$ & $g_{M e d}$ & $g_{K S}$ & KS statistics & $\pi$ \\
\hline $2000-01$ & $0.11(0.01)$ & 0.08 & 0.09 & 1.21 & 0.06 \\
$2001-02$ & $\mathbf{0 . 0 0}(0.02)$ & -0.02 & $\mathbf{0 . 0 0}$ & 0.85 & 0.05 \\
$2002-03$ & $0.05(0.02)$ & 0.02 & 0.06 & 1.36 & 0.02 \\
$2003-04$ & $0.11(0.02)$ & 0.07 & $\mathbf{0 . 1 0}$ & 0.85 & 0.03 \\
$2004-05$ & $0.18(0.02)$ & 0.10 & 0.15 & 1.51 & 0.04 \\
$2005-06$ & $0.14(0.02)$ & 0.11 & 0.14 & 1.35 & 0.06 \\
$2006-07$ & $0.16(0.02)$ & 0.10 & 0.13 & 1.16 & 0.05 \\
$2007-08$ & $\mathbf{0 . 0 6}(0.02)$ & $\mathbf{0 . 0 5}$ & $\mathbf{0 . 0 5}$ & 0.48 & 0.13 \\
$2008-09$ & $\mathbf{0 . 0 1}(0.02)$ & $\mathbf{0 . 0 2}$ & $\mathbf{0 . 0 2}$ & 0.44 & 0.12 \\
\hline
\end{tabular}

Table 4 The table shows the estimation of the measure of central tendency for the growth rates distribution, performed with three different estimators: the mean, the median and by minimizing the KS statistics. The associated errors for all three methods is the error of the mean computed with the usual standard method. The bold estimates indicate that the Laplace benchmark cannot be rejected at $1 \%$ significance level.

higher persistence in the profitability of firms than in the way they manage their assets. It might be an indication that the driving force of the dynamics of firms can be found in their profitability and not in the way they grow or shrink over time. In future work we will analyze more in detailed in how far profit and growth rates can be considered proxies and in how far they exhibit different statistical properties. 


\section{Concluding remarks}

In this paper we have verified that one size measure of Icelandic firms, namely total assets, follows a power-law distribution, with an exponent above unity, during the period 2000-2009, in line with previous contribution from the pertinent literature. Although, we find a period within the data set, 2006-2008, which coincides with the peak of the economic boom in Iceland where we reject the null hypothesis that the data follows a power-law distribution. This deviation seems to be related to an inflow of small firms during the booming period of the economy.

Using a very general framework for the Laplacian hypothesis of profit rates distribution introduced by Alfarano et al. (2012) we have shown that the Laplace distribution is a good benchmark for the distribution of profit rates, even in a very small economy where most firms are privately owned as is the case in Iceland. The exception is, as with the power-law distribution of firms size, during the peak of the economic boom. The symmetric Laplace distribution can be thought of as a kind of statistical equilibrium distribution which characterizes a phase of equilibrated growth of an economy. Our tentative hypothesis is that in periods of high growth (bubble) of the economy, this equilibrium is broken in favor of a distribution characterized by significant asymmetry.

Contrary to the profit rates, the laplacian benchmark for growth rates seems not to adequately describe the empirical probability density of growth rates of Icelandic firms. The laplacian null hypothesis is, in fact, rejected in almost all cases according to the KS test. Following our analysis of profit rates, we employ different methods for the estimation of the measure of central tendency. Interestingly, its statistics seems to have the same pattern as observed for the profit rates, namely during the booming period the value of the KS statistics for the different definitions of $m$ increases, which coincides with the evident asymmetry of the distribution, signaled by the significant difference between mean and median.

Even if the two unconditional distribution of profit and growth rates might be more or less satisfactorily described by the underlying benchmark distribution, namely the Laplace, they exhibit some remarkable differences. It seems that there is a much higher persistence in the profitability of firms than in the way they manage their assets. It might be an indication that the driving force of the dynamics of firms can be found in their profitability and not in the way they grow or shrink.

In future work we will analyze in more detail in how far profit and growth rates can be considered proxies and in how far they exhibit different statistical properties. Additionally, since we observe deviations from the typically identified distributional properties during a high growth of an economy, we can tentatively state that in period of booming, some distributional stylized facts might not hold. Our hypothesis should be confirmed analyzing other booming European economies, like Spanish and Irish for instance. 


\section{Acknowledgements}

The authors would like to acknowledge the financial support of the Icelandic Center for Research (RANNIS) grant no. 110653021. EJE would also like to acknowledge financial support of the COST Action IS0902, for a short visit to University Jaume I, Castellón, Spain, where the paper was completed.

\section{References}

[Alfarano and Milakovic(2008)] Alfarano S, Milakovic M (2008) Does classical competition explain the statistical features of firm growth? Economics Letters 101(3):272-274

[Alfarano et al(2012)Alfarano, Milakovic, Irle, and Kauschke] Alfarano S, Milakovic M, Irle A, Kauschke J (2012) A statistical equilibrium model of competitive firms. Journal of Economic Dynamics and Control 36:136-149

[Atalay et al(2011)Atalay, Hortasu, Roberts, and Syverson] Atalay E, Hortasu A, Roberts J, Syverson C (2011) Network structure of production. Proceedings of the National Academy of Sciences 108(13):5199

[Axtell(2001)] Axtell R (2001) Zipf distribution of us firm sizes. Science 293(5536):1818

[Baek et al(2011)Baek, Bernhardsson, and Minnhagen] Baek S, Bernhardsson S, Minnhagen P (2011) Zipf's law unzipped. New Journal of Physics 13:043,004

[Bottazzi and Secchi(2006)] Bottazzi G, Secchi A (2006) Explaining the distribution of firm growth rates. The RAND Journal of Economics 37(2):235-256

[Champernowne(1953)] Champernowne D (1953) A model of income distribution. Economic Journal 83:318-351

[Cincotti et al(2010)Cincotti, Raberto, and Teglio] Cincotti S, Raberto M, Teglio A (2010) Credit money and macroeconomic instability in the agent-based model and simulator eurace. The Open-Access, Open-Assessment E-Journal 4(2010-26)

[Cirillo(2010)] Cirillo P (2010) An analysis of the size distribution of italian firms by age. Physica A: Statistical Mechanics and its Applications 389(3):459-466

[Cirillo and Hüsler(2009)] Cirillo P, Hüsler J (2009) On the upper tail of italian firms' size distribution. Physica A: Statistical Mechanics and its Applications 388(8):1546-1554

[De Wit(2005)] De Wit G (2005) Firm size distributions:: An overview of steady-state distributions resulting from firm dynamics models. International Journal of Industrial Organization 23(5-6):423-450

[Farmer and Foley(2009)] Farmer J, Foley D (2009) The economy needs agent-based modelling. Nature 460(7256):685-686

[Gabaix(2009)] Gabaix X (2009) Power laws in economics and finance. Annual Review of Economics 1(1):255-294

[Gatti et al(2005)Gatti, Guilmi, Gaffeo, Giulioni, Gallegati, and Palestrini] Gatti DD, Guilmi C, Gaffeo E, Giulioni G, Gallegati M, Palestrini A (2005) A new approach to business fluctuations: heterogeneous interacting agents, scaling laws and financial fragility. Journal of Economic Behavior \& Organization 56(4):489-512

[Gibrat(1931)] Gibrat R (1931) Les Ingalits Economique. Sirely, Paris

[Ijiri and Simon(1974)] Ijiri Y, Simon HA (1974) Interpretations of departures from the pareto curve firm-size distributions. Journal of Political Economy 82(2):315-31

[M. L. Goldstein(2004)] M L Goldstein GGY S A Morris (2004) Problems with fitting to the power-law distribution. The European Physical Journal B 41(2):255-258

[Myers(1984)] Myers S (1984) The capital structure puzzle. The Journal Of Finance 39(3)

[Podobnik et al(2010)Podobnik, Horvatic, Petersen, Uroevi, and Stanley] Podobnik B, Horvatic D, Petersen A, Uroevi B, Stanley H (2010) Bankruptcy risk model and empirical tests. Proceedings of the National Academy of Sciences 107(43):18,325

[Puig and Stephens(2000)] Puig P, Stephens M (2000) Tests of fit for the laplace distribution, with applications. Technometrics pp 417-424

[Raberto et al(2011)Raberto, Teglio, and Cincotti] Raberto M, Teglio A, Cincotti S (2011) Debt deleveraging and business cycles. an agent-based perspective (2011-31), URL http://www.economics-ejournal.org/economics/discussionpapers/2011-31 
[Simon and Bonini(1958)] Simon H, Bonini C (1958) The size distribution of business firms. The American Economic Review 48(4):607-617

[Smets et al(2002)Smets, Wouters, and Europeo] Smets F, Wouters R, Europeo BC (2002) An estimated stochastic dynamic general equilibrium model of the euro area. European Central Bank

[Stanley et al(1996)Stanley, Amaral, Buldyrev, Leschhorn, Maass, Salinger, and Stanley] Stanley M, Amaral LAN, Buldyrev SV, Leschhorn H, Maass P, Salinger M, Stanley HE (1996) Scaling behavior in the growth of companies. Nature 379:804-806 